\title{
Inovação, políticas públicas de apoio e seus impactos sociais: resgate teórico sobre os temas
}

\author{
Innovation, public support policies and their social impacts: theoretical \\ rescue on the themes
}

\author{
Alexandre Aloys Matte Júnior \\ Universidade do Vale do Rio dos Sinos - São Leopoldo - Rio Grande do Sul - Brasil \\ ORCID https://orcid.org/0000-0002-8083-5002
}

\begin{abstract}
Resumo: Apesar de as políticas públicas de apoio a inovação priorizarem o desenvolvimento das organizações, é necessário entender que seu impacto dá voz à população e possibilita inovações capazes de impactar de forma positiva o desenvolvimento social regional. Assim, este artigo tem como objetivo avaliar a importância da formulação de políticas regionais e iniciativas voltadas à inovação e impacto destas sobre atores sociais. Para tanto, a pesquisa foi desenvolvida a partir de pesquisa bibliográfica, valendo-se de consulta à periódicos e livros das áreas de ciências sociais e ciências sociais aplicadas para contemplar os objetivos de pesquisa. Após o levantamento teórico, evidencia-se que a luta pelo poder e por recursos entre os grupos sociais é o cerne da formulação de políticas públicas, sendo essa luta mediada por instituições políticas e econômicas que levam as políticas públicas para certa direção e privilegiam alguns grupos em razão de outros. No que tange o impacto social de políticas públicas voltadas à inovação, verificou-se que a ação conjunta de empresas e outros agentes locais ocasiona a criação de diferentes tipos de instituições de ensino, pesquisa e prestação de serviços que impactam no aumento da capacidade de inovação do sistema e as externalidades positivas locais.
\end{abstract}

Palavras-chave: políticas públicas; inovação; impacto social; externalidades positivas.

Abstract: Although public policies that support innovation prioritize the development of organizations, it is necessary to understand that their impact gives voice to the population and enables innovations that can positively impact regional social development. Thus, this article aims to evaluate the importance of regional policy formulation and innovation initiatives and their impact on social actors. So, the research was developed from bibliographical research, consulting journals and books from the social sciences and applied social sciences to contemplate the research objectives. After the theoretical survey, it is evident that the struggle for power and resources between social groups is the core of the formulation of public policies, and this struggle is mediated by political and economic institutions that take public policies in a certain 
Inovação, políticas públicas de apoio e seus impactos sociais: resgate teórico sobre os

temas

direction and favor some groups instead of others. Regarding the social impact of innovation-oriented public policies, it was found that the joint action of companies and other local agents leads to the creation of different types of educational, research and service delivery institutions that impact on the increase of innovation capacity system and local positive externalities.

Keywords: public policies; innovation; social impact; positive externalities.

\section{Introdução}

Pode-se definir inovação como a capacidade das organizações se renovarem e diferenciarem-se continuamente, abrangendo o desenvolvimento de novos processos, produtos, métodos, mercados, entre outros fatores. Um dos primeiros autores a destacar a inovação foi Schumpeter (1912), afirmando sobre a necessidade dela para a concretização de resultados maiores, através do lançamento de produtos novos, alcançando assim a organização a um status monopolista, mesmo que temporário. $\mathrm{Na}$ opinião do autor, é o produtor que inicia uma mudança econômica, refletindo no comportamento do consumidor, sendo estes "ensinados" a quererem coisas novas ou que contemplem alguma inovação. Drucker (2005) diz que a inovação é um meio pelo qual explora-se a mudança como uma oportunidade para um negócio ou serviço diferente. Tidd, Bessant e Pavitt (2008) afirmam que a inovação é movida pela habilidade de estabelecer relações, detectar oportunidades e tirar proveito das mesmas, não consistindo apenas em um fato isolado, mas um processo contínuo, e como tal, necessita gerenciamento.

A inovação é crucial para o desenvolvimento das organizações, regiões e nações. Ela possui caráter sistêmico e é dentro destes em que se desenvolvem e se aplicam políticas públicas, almejando alcançar o bem-estar da sociedade. No geral, as políticas públicas voltadas à inovação são em forma de incentivos fiscais e apoio a pesquisa e desenvolvimento ligados à tecnologia, ciência e pesquisa, e que acabam impactando diretamente o meio social (MURAN; MARINI; PERONDI, 2016). Além disso, a inovação deve servir à rentabilidade econômica das empresas e ainda mais à melhoria da qualidade de vida das pessoas, com viés ligado à sustentabilidade, melhorarias no desempenho das organizações, acréscimos em práticas sociais e desenvolvimento para a economia regional (FRANZIN; ALMEIDA; SOUZA, 2014; MURAN; MARINI; PERONDI, 2016)

Nesse sentido, o governo possui papel importante em relação à inovação, investindo recursos e permitindo o desenvolvimento das organizações e, por consequência, da economia do país. O processo de inovação demanda recursos que possibilitam às organizações adquirirem novas tecnologias, organizarem atividades, processos e produtos novos, diversificarem seu portfólio e a investirem em atividades contínuas de pesquisa e desenvolvimento, o que torna o papel do setor público crucial no sentido de criar condições para que isso ocorra (MURAN; MARINI; PERONDI, 2016). Nesse sentido, o estudo e desenvolvimento de políticas públicas adequadas também recebe destaque. O campo das políticas públicas, conforme Souza (2006) tem ganho 
Inovação, políticas públicas de apoio e seus impactos sociais: resgate teórico sobre os temas

maior visibilidade nas últimas décadas, sendo um dos fatores a adoção de políticas restritivas de gastos, que passaram a dominar a maioria dos países, o desenho e execução de políticas públicas, tanto de ordem econômica como as sociais, exatamente pela sua capacidade de promover mudanças significativas.

Dentro dessa problemática, constitui-se o questionamento central da pesquisa: Qual a importância de políticas públicas de apoio à inovação para o desenvolvimento econômico e social de uma região? Como objetivo central, busca-se avaliar a importância da formulação de políticas regionais e iniciativas voltadas à inovação e impacto destas sobre atores sociais. Dispondo em objetivos específicos, busca-se: a) levantar o impacto social da estruturação e estímulo à ecossistemas de inovação; b) contextualizar políticas públicas, trazendo autores que possam colaborar com isso, e c) avaliar de que forma os atores e movimentos sociais se mobilizam em prol do desenvolvimento de políticas públicas, inclusive focando no estímulo à ecossistemas de inovação.

Assim, este estudo justifica-se, pois se torna essencial o aprofundamento das políticas públicas, de forma geral, e mais ainda as de apoio à inovação, bem como da forma de organização dos atores sociais em relação a isso. Para Franzin, Almeida e Souza (2014), caso hajam pesquisadores ou grupos de trabalho de órgãos públicos que aprofundem o estudo da inovação no contexto do desenvolvimento regional, haverão ganhos consideráveis na produção científica e fortalecimento de arranjos produtivos locais (APLs). Com isso, estes podem se valer do uso de ferramentas de gestão da inovação no desenvolvimento de políticas públicas, visando a avaliação e o refinamento do planejamento. Além disso, na visão de Muran, Marini e Perondi (2016), o fomento à inovação a partir de políticas públicas também permite aprimorar empresas, desenvolver arranjos produtivos locais, gerar emprego e renda, além de estimular a exportação. Ainda, a importância do estudo de políticas públicas é sintetizada por Cortes e Lima (2012), onde frisam a complexidade existente na relação entre Estado e sociedade, uma das razões pelas quais as políticas públicas são intrinsecamente interdisciplinares.

Com relação aos procedimentos metodológicos, a pesquisa foi desenvolvida a partir de pesquisa bibliográfica, adotando viés qualitativo, valendo-se de consulta à periódicos e livros das áreas de ciências sociais e ciências sociais aplicadas para contemplar os objetivos de pesquisa, buscando avaliar literatura relacionada a políticas públicas, atores e mobilização social e impactos de políticas públicas voltadas à inovação. Conforme Creswel (2010) pesquisas dessa natureza cumprem vários propósitos, compartilhando e relacionando estudos já realizados, proporcionando referência para comparação com outros resultados. Dessa forma, as publicações foram analisadas e delas extraídos os principais resultados. Na sequência, foram relacionadas as percepções e contribuições dos autores, sendo que os conteúdos em síntese referemse a: (i) conceitos relacionados à políticas públicas; (ii) atores sociais, cidadania e movimentos sociais e (iii) impacto regional de políticas públicas de inovação.

Além desta introdução, este artigo está organizado da forma descrita a seguir. Na próxima seção apresentam-se os conceitos de políticas públicas, formulação e ciclos, 
Inovação, políticas públicas de apoio e seus impactos sociais: resgate teórico sobre os temas

atores sociais, entre outros conceitos relevantes. A seção três apresenta contribuições dos autores sobre cidadania e movimentos sociais e mobilização destes. Já na seção quatro são apresentadas as contribuições relacionadas às políticas de fomento à inovação e impacto regional e social destas. Por fim, apresentam-se as considerações finais resultantes do desenvolvimento da pesquisa.

\section{Políticas públicas: conceitos gerais}

Nessa seção, abordam-se conceitos gerais sobre políticas públicas, sua formulação, ciclo e avaliação, buscando sintetizar de forma pragmática e entendível, reforçando-se que se constitui em campo amplo para estudos.

Como área de conhecimento, a política pública nasce como disciplina acadêmica nos EUA, rompendo com a tradição europeia, que possuía pesquisas e trabalhos focados na análise sobre o Estado e suas instituições, e não na produção dos governos. Nos EUA, a área surge no mundo acadêmico, passando a enfatizar a ação dos governos nos estudos conduzidos. No âmbito governamental, a introdução da política pública é produto da Guerra Fria e da valorização da tecnocracia (Souza, 2006). O campo de estudo de políticas públicas, de acordo com Souza (2006), vem adquirindo cada vez mais relevância devido às novas visões sobre o papel do governo, que passam a adotar postura de restrição e gastos. A autora também ressalta que, o que demonstra essa relevância é que, mais diretamente relacionado aos países em desenvolvimento e de democracia recente, ainda há dificuldades em se formar coalizões políticas para equacionar a questão de como desenhar políticas públicas capazes de impulsionar o desenvolvimento econômico e de promover a inclusão social da maioria da população.

Aplicando uma definição funcional de política pública, Howlet, Ramesh e Perl (2013) sintetizam que o "fazer política" trata fundamentalmente de atores cercados por restrições que tentam compatibilizar objetivos políticos com meios políticos, em um processo caracterizado pela resolução de problemas. Porém, os autores ressaltam que identificar os problemas e aplicar as soluções encontradas envolvem a articulação de objetivos políticos através de deliberações e discursos, além de se valerem de instrumentos políticos para tentar atingir os objetivos. Lynn (1980) apud Souza (2006) define política pública como um conjunto de ações do governo que irão produzir efeitos específicos, bem como Dye (1984) apud Souza (2006) que afirma que política pública consiste no que o governo escolhe fazer ou não fazer. Uma das definições mais conhecidas é a de Laswell, que diz que decisões e análises sobre política pública implicam em respostas às questões a) quem ganha o quê; b) por quê e c) que diferença faz. Souza (2006, p. 40) diz que o foco central da política pública reside na identificação do tipo de problema "[...] que a política pública visa corrigir, na chegada desse problema ao sistema político (politics) e a à sociedade política (polity), e nas instituições/regras que irão modelar a decisão e a implementação da política pública".

Qualquer política pública precisa explicar as interrelações entre Estado, política, economia e sociedade, uma vez que é multidisciplinar. 
Pode-se, então, resumir política pública como o campo do conhecimento que busca, ao mesmo tempo, "colocar o governo em ação" e/ou analisar essa ação (variável independente) e, quando necessário, propor mudanças no rumo ou curso dessas ações (variável dependente). A formulação de políticas públicas constitui-se no estágio em que os governos democráticos traduzem seus propósitos e plataformas eleitorais em programas e ações que produzirão resultados ou mudanças no mundo real. (SOUZA, 2006, p. 26).

De forma geral, as definições em relação à política pública adotam a perspectiva de que o todo é mais importante do que a soma das partes e que indivíduos, instituições, interações, ideologia e interesses contam, mesmo existindo diferenças sobre a importância relativa destes. Após desenhadas e formuladas, as políticas públicas se desdobram em planos, programas, projetos, bases de dados ou sistemas de informações e pesquisas, além de, quando implementadas, se submeterem a sistemas de acompanhamento e avaliação (SOUZA, 2006).

Falando sobre a Formulação das políticas públicas, David, Fonseca e Pereira (2018) afirmam que esta parte envolve um conjunto de processos que incluem, ao menos, o estabelecimento de uma agenda, especificação de alternativas que servirão de base para as escolhas, escolha final entre estas alternativas, por meio de votação do Legislativo ou decisão do Executivo e posterior implementação desta decisão. Os processos de montagem da agenda são contingentes, mas muitas vezes ainda previsíveis, envolvendo as interrelações de ideias, atores e estruturas. Além disso, a natureza dos atores que iniciam as discussões políticas e as condições favoráveis ao surgimento de novas ideias nas estruturas, são os fatores mais relevantes da ascensão dos problemas públicos da agenda informal para a agenda institucional do Estado (HOWLET; RAMESH; PERL, 2013). Importante também o timing exato do surgimento de uma questão na agenda formal, a existência de uma janela política e da capacidade e habilidade dos empreendedores políticos se valerem dela. Também, o conteúdo dos problemas identificados no processo de sua montagem depende muito da natureza do subsistema político presente na área em jogo e dos tipos de ideias que seus membros detêm e sustentam (HOWLET; RAMESH; PERL, 2013).

Por sua vez, a implementação da política pública consiste em um conjunto de decisões e ações realizadas por grupos ou indivíduos, tanto públicos ou privados, focados na consecução de objetivos previamente estabelecidos através de decisões anteriores de determinada política pública (DAVID, FONSECA E PEREIRA, 2018). Howlet, Ramesh e Perl (2013), falando sobre a implementação de políticas, frisam que está se compreende o estágio de implementação do ciclo político e que, enquanto a maioria das decisões políticas identifica os meios para perseguir seus objetivos, as escolhas subsequentes precisam alcançar resultados, sendo que para que uma política funcione, há de se alocar fundos, designar pessoas e desenvolver regras de como proceder. A implementação de políticas depende, muitas vezes, de servidores públicos e funcionários administrativos, entretanto, atores não governamentais que fazem parte do subsistema político-administrativo também podem participar nas atividades de implementação (HOWLET; RAMESH; PERL, 2013). 
Inovação, políticas públicas de apoio e seus impactos sociais: resgate teórico sobre os temas

O monitoramento (acompanhamento contínuo por parte dos gestores) e avaliação de políticas públicas são essenciais, integrando-se ao ciclo de forma que o acompanhamento da implementação e os ajustes a serem adotados para manutenção, aperfeiçoamento ou interrupção de políticas públicas sejam realizados. A reformulação vem em seguida, fruto do monitoramento e avaliação das políticas públicas (David, Fonseca e Pereira, 2018), como disposto na Figura 1.

Figura 1 - Ciclo de Política Pública

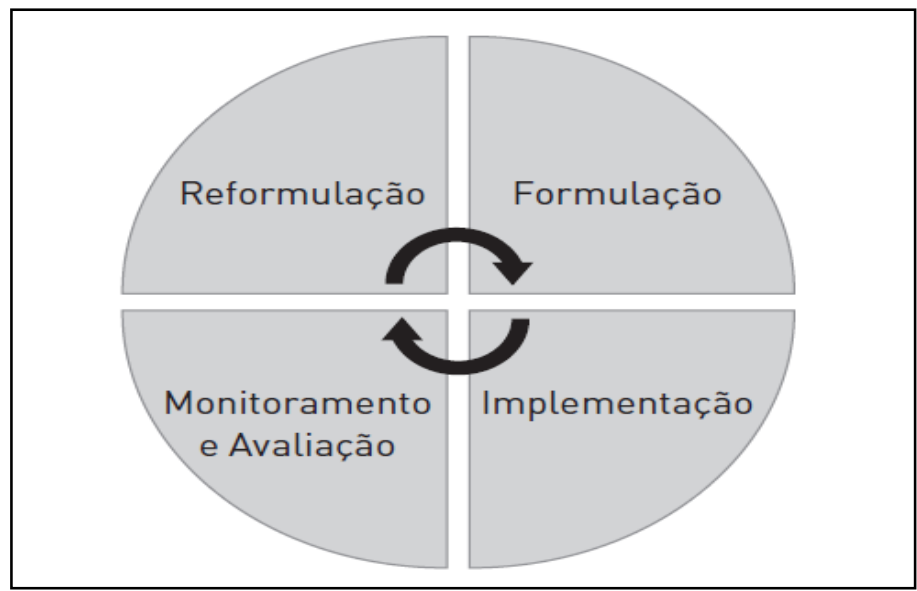

Fonte: David, Fonseca e Pereira (2018)

Tratando sobre a análise e avaliação de políticas públicas, David, Fonseca e Pereira (2018) citam que a literatura divide o ciclo de políticas públicas em fases que se articulam e se retroalimentam, podendo indicar ajustes necessários ao aperfeiçoamento das políticas públicas. As fases desse ciclo caracterizam-se como a) formulação; b) implementação; c) monitoramento e avaliação e: d) reformulação.

Dentro do campo de estudo das políticas públicas, foram desenvolvidos modelos explicativos para melhor se entender como e porque o governo faz ou deixa de fazer alguma ação que possa ter impacto na sociedade (SOUZA, 2006). Dos diversos modelos e definições de políticas públicas, Souza (2006) sintetiza seus elementos principais, citando que a política pública permite distinguir entre o que o governo pretende fazer e o que efetivamente faz, além de, embora materializada nos governos, envolver vários atores e níveis de decisão, não se restringindo a participantes formais, uma vez que os informais também possuem importante papel. A autora ainda sintetiza que a política pública é abrangente e não se limita a leis e regras, além de caracterizar-se como uma ação intencional, com objetivos a serem alcançados. Também, embora tenha impacto no curto prazo, a política pública é uma política de longo prazo, envolvendo, após sua decisão e proposição, etapas como a implementação, execução e avaliação.

\section{a - Atores sociais: características}

Segundo David, Fonseca e Pereira (2018), atores de políticas públicas consistem naqueles cujos interesses são afetados, tanto positiva como negativamente, por 
Inovação, políticas públicas de apoio e seus impactos sociais: resgate teórico sobre os temas

decisões e ações de uma determinada política, sendo que os atores variam ao longo do tempo e conforme a política pública específica. Nesse sentido, as intensas migrações, transformações econômicas, culturais e no mercado de trabalhado, ao influenciarem a constituição de novos atores coletivos, acabam por acirrar a luta por reconhecimento destes. A sociologia utiliza esses novos atores como objetos de estudo, examinando seus ideais, discursos produzidos por e sobre eles, ação política destes, além da própria construção desses grupos "[...] a partir da ação estatal que os reconhece, hierarquiza e os institui como beneficiários de políticas e como atores societais" (CORTES; LIMA, 2012, p. 38).

Pode-se dividir os atores em públicos e privados, sendo os atores públicos aqueles que desempenham uma função pública e atuam regidos pelos interesses públicos e/ou utilizam recursos de natureza pública, servindo como exemplo os políticos e os burocratas. Já os atores privados são, como o próprio nome sugere, aqueles que operam na esfera privada, na esfera econômica ou em atividades extra materiais, como valores éticos e morais, religião, etnia e gênero, compreendendo empresários, trabalhadores, grupos de interesses, associações civis e religiosas, sindicatos, ONGs, partidos políticos, movimentos sociais, entre outros. Podem atuar formalmente, com papéis pré-determinados, e informalmente, participando de redes de políticas públicas e coalizões de defesa, por exemplo (DAVID; FONSECA; PEREIRA, 2018). Independente da sua categorização, importante ressaltar a consideração de Souza (2006), que ressalta, através de pressupostos da teoria neo-institucionalista, que a luta pelo poder e por recursos entre os grupos sociais é o cerne da formulação de políticas públicas, sendo essa luta mediada por instituições políticas e econômicas que levam as políticas públicas para certa direção e privilegiam alguns grupos em razão de outros.

Os atores também podem ser classificados como visíveis e invisíveis. No caso dos visíveis, consistem em personas que normalmente aparecem na mídia, como o Presidente da República, prefeitos, etc. Já os invisíveis consistem são os que aparecem de forma mais pontual perante o público, como acadêmicos, assessores internos e externos do governo, entre outros (David, Fonseca e Pereira, 2018). O autor ainda afirma que atores de políticas públicas possuem interesses individuais e buscam satisfazê-los por meio de estratégias. Em diferentes fases, empregam seus recursos de poder, como a força política, recursos financeiros, informação e capacidade de gestão para apoiar ou rejeitar as decisões tomadas, entre outros.

Assim, nesse sentido, empregando seus recursos de poder, financeiros, entre outros, Abers, Silva e Tatagiba (2018) comentam que, sem espanto algum, as análises realizadas demonstram a importância de ativistas com múltiplas filiações, seja a partidos, movimentos sociais, órgãos do governo e/ou associações profissionais, fazendo com que as demandas dos movimentos alcancem o Estado e também para facilitando a formulação da demanda como uma política pública. Os estudos também apontam que o esforço dos movimentos sociais para influenciar as políticas tem alterado a configuração dos setores, criando institucionalidades como ministérios, secretarias e Instituições Participativas (ABERS; SILVA; TATAGIBA, 2018). Como exemplo dessa influência, Serafim (2013) apud Abers, Silva e Tatagiba (2018) aborda a inserção 
Inovação, políticas públicas de apoio e seus impactos sociais: resgate teórico sobre os

temas

de militantes do Fórum da Reforma Urbana nos governos petistas e o impacto sobre a conformação do Ministério das Cidades e Silva, Rocha e Alves (2012) apud Abers, Silva e Tatagiba (2018) analisaram as interdependências entre as configurações associativas em dois Territórios da Cidadania (Na Bahia e no Rio Grande do Sul), e a implementação da Política de Desenvolvimento Territorial. É possível trazer outros exemplos desse impacto dos movimentos e da atuação dos atores sociais, os casos têm sido recorrentes no Brasil.

Também, interagindo, os atores podem se comportar de diferentes formas para influenciar as políticas públicas e se beneficiarem delas, sendo que David, Fonseca e Pereira (2018) citam quatro tipos de interação, que consistem em lutas, jogos, debates e pressão pública. $O$ autor cita que a luta implica alto grau de conflito, onde a vitória dos interesses de um ator gera a derrota dos demais. Os jogos são mais corriqueiros na política, e sua lógica é a da competição, no qual os atores buscam vencer os adversários sem eliminá-los da competição, através de negociações, barganhas e acordos políticos. Nos debates, um ator busca convencer o outro dos seus argumentos e da adequação das propostas. Por fim, a pressão pública é a interação na qual ocorrem ações, como manifestações coletivas, uso da imprensa e greves, entre outros, para chamar a atenção da opinião pública para um determinado problema político (DAVID; FONSECA; PEREIRA, 2018).

\section{b - Cidadania e movimentos sociais}

Conforme Rego (2008), a consolidação da cidadania, como processo político institucional e como fonte de cultura democrática, transita em percurso que foi e é longo e difícil. Os direitos foram desejados e obtidos pelos seus destinatários, foram conquistados, mas, por outro lado, foram e são um motivo e um objeto de conflito permanente. Essa continuidade também é reforçada pela autora quando diz que "de certo modo, pode-se afirmar que a grande tradição do pensamento político e social ocidental sempre soube que cidadania (civitas) é um processo social essencialmente político constituído de um fazer-se contínuo" (p. 159).

A cidadania, como processo de aquisição de direitos e de capacidades para seu gozo por parte das pessoas, portanto, como direito e capacidade para participar da herança material e cultural da civilização, funda a possibilidade de implementação de processos políticos democráticos incessantes de expansão e normatização de novos direitos. Isto faz com que os cidadãos experimentem mais plenamente sua condição de partícipes de uma comunidade humana integrada e coesa que pode ser uma Nação, mas que tenha como medida padrões universais de valores e de bem-estar material. (REGO, p. 171).

A participação cidadã, dessa forma, permite que os cidadãos se sintam ativos na expansão e busca de seus direitos e transformação da sociedade em que estão inseridos. Nesse contexto, políticas públicas que privilegiem a constituição e amadurecimento de um ecossistema de inovação acabam por criar um ambiente em que a cidadania 
Inovação, políticas públicas de apoio e seus impactos sociais: resgate teórico sobre os temas

também é privilegiada. Isso se torna positivo, colaborando a afirmação de Rego (2008), quando cita que "um ideal exigente de cidadania pode gerar critérios e princípios para as instituições, para as políticas e, afinal, para a ação coletiva e a reforma social" (p. 172).

Esse anseio pela participação, por sentir-se parte, pela democracia, encontra ganchos na história recente de nosso país. Já no início dos anos 1990, a sociedade brasileira começava a conviver com movimentos sociais que não se resumiam a dimensões de direitos civis e políticos, reivindicando direitos sociais, econômicos, bem como direitos de ordem subjetiva, tais quais ao meio ambiente, a paz e controle da violência social (Viola; Pires, 2014). A partir dos anos 2000, a agenda de pesquisas enfatizou os resultados da participação dos movimentos, demonstrando que estes produzem mudanças na política pública ao integrarem redes e comunidades de políticas públicas, nesse sentido interagindo com outros atores sociais e estatais, sendo que os estudos ainda expõem que o espaço de atuação dos movimentos, bem como resultados obtidos, são condicionados pela trajetória institucional de cada política e formas históricas com que foram construídos vínculos com atores políticos relevantes (ABERS; SILVA; TATAGIBA, 2018).

O início do século XXI apresentou um novo ciclo de participação da juventude, de acordo com Viola e Pires (2014), caracterizado pela formação de sujeitos coletivos que buscam formas participativas de organização e tomada de decisão, demonstrando capacidade inovadora de se aproximar de uma pluralidade de interesses em torno de bandeiras que não ficam limitadas apenas à mudanças na estrutura do Estado, mas que requerem criação de formas de democracia direta e plural. São movimentos em oposição direta às medidas de deterioração dos direitos sociais e econômicos, estes anunciados na Constituição, mas relegados pelo Estado.

Igualmente, a importância da mobilização dos movimentos e atores sociais é expressa, por exemplo, no trabalho de Santos (2016) onde este reforça a atuação e mobilização de movimentos negros urbanos para a constituição e promoção de políticas de ação afirmativa no Brasil e na Colômbia, exercendo pressão política para que mudanças fossem realizadas e levadas a cabo. O trabalho de López (2013) também exemplifica a mobilização das mulheres negras do Uruguai, focando a constituição do sujeito político mulher negra no Uruguai nos contextos de disputas travadas pelo movimento afro-uruguaio e de reconfigurações nas relações com o Estado. Além disso, Maciel (2011) contribui resgatando a mobilização realizada para a Lei Maria da Penha, citando que as primeiras mobilizações feministas tiveram início na segunda metade dos anos 1990, contemplando múltiplas dimensões da ação coletiva, desde a estrutura de oportunidades políticas, as carreiras de ativismo, os quadros interpretativos e as estratégias adotadas no curso das mobilizações para a mudança legal.

Abers, Silva e Tatagiba (2018) frisam que o estudo da inserção de movimentos sociais no processo de produção das políticas públicas, condições que favorecem ou limitam sua influência na modelagem das políticas e redes dentro e fora do Estado tem gerado uma importante agenda, sendo que alguns frutos já são demonstrados, como o reconhecimento da mútua constituição, ou seja, de que os movimentos sociais 
Inovação, políticas públicas de apoio e seus impactos sociais: resgate teórico sobre os temas

importam para as políticas públicas e que estas, por sua vez, impactam no desenvolvimento, sucesso e até mesmo emergência destes movimentos.

Em seu modelo, Abers, Silva e Tatagiba (2018) enfatizam a relevância dos regimes políticos e os subsistemas de políticas públicas, citando sua importância, uma vez que, no contexto político, "os estudos realizados sobre o caso brasileiro têm demonstrado empiricamente que o contexto político importa para a forma como movimentos sociais influenciam (ou não) a política pública e os resultados que alcançam nesse processo" (p.18). Em resumo, regimes são liderados por coalizações governantes e compostos pela estrutura das relações entre atores politicamente relevantes da sociedade e do Estado e destes com arranjos de instituições, regras e ideias previamente estabelecidos por conflitos políticos e políticas públicas anteriores (ABERS, SILVA E TATAGIBA, 2018). Após sintetizar o que são regimes, Abers, Silva e Tatagiba (2018, p. 33) dizem que "[...] a posição ocupada pelos atores e interesses dos movimentos sociais no regime define oportunidades e/ou obstáculos para reconhecimento, acesso e influência institucional de tais atores e interesses". Assim, em diferentes regimes, os movimentos sociais também terão diferentes possibilidades de avançarem em suas causas em função do lugar que ocupam no regime e na relação que possuem com a ou na coalização governante.

Já os subsistemas possuem uma dinâmica que independe parcialmente do regime vigente, onde as comunidades de políticas que os integram debatem propostas e buscam colocar ideias na agenda, recorrentemente a despeito dos interesses expressos pelas coalizações de governo. Para Howlett e Ramesh (1998) apud Abers, Silva e Tatagiba (2018), "[...] o conceito de subsistemas possibilita identificar a existência não somente de atores estatais e grupos de interesse, mas também de grupos mobilizados por expertise ou comprometimento com um tema" (p.35). Jenkins-Smith, St. Clair e Woods (1991) apud Abers, Silva e Tatagiba (2018) citam que membros de subsistemas incluem representantes de empresas, grupos de interesses, associações comerciais, órgãos do executivo e comissões legislativas, bem como autoridades eleitas, estudiosos e jornalistas que regularmente acompanham e buscam influenciar o curso de uma política pública na área temática. Assim, Abers, Silva e Tatagiba (2018) dizem que subsistemas aparecem como arenas de disputa, sendo a dinâmica de subsistemas caracterizada pelo conflito entre diferentes ideias, defendidas por diferentes coalizões, o que resulta em mudança ou "aprendizado", levando-se em conta que ideias não antecedem as interações entre os atores, mas são construídas e transformadas através delas.

Expondo a relação entre regime e subsistema, Abers, Silva e Tatagiba (2018, p. 36) explicam que:

[...] enquanto o regime nos permite tematizar as configurações relacionais de poder que importam para a ação dos movimentos sociais sobre as políticas públicas, o conceito de subsistema nos permite captar as variações no interior do regime em razão das configurações de poder específicas a cada setor de política pública, que conferem aos movimentos sociais diferentes condições de acesso e influência. Sob uma mesma coalizão de governo, subsistemas de 
Inovação, políticas públicas de apoio e seus impactos sociais: resgate teórico sobre os temas

políticas públicas podem variar significativamente na sua abertura à atuação de movimentos sociais.

As configurações são distintas e produzem diferentes possibilidades de participação, dada a configuração da agência, relacionamento e desigualdades de poder dos diversos atores que a integram. Até mesmo quando membros dos movimentos sociais ocupam posições de destaque dentro do regime, as possibilidades de acesso aumentam, da mesma forma que mudanças na coalizão também possuem efeito contrário, fazendo com que a capacidade de influência dos movimentos sociais sofra decréscimos. Nessa perspectiva, os movimentos sociais não se relacionam com o regime ou com os subsistemas, mas no regime e no subsistema, no interior destes (ABERS, SILVA E TATAGIBA, 2018).

\section{Impacto regional e social de políticas públicas de inovação}

Tratando sobre a importância dos atores na criação de ambiente propício à inovação, Cândido (2002) enaltece o papel do Estado, sugerindo que este deve encorajar a formação de uma estrutura econômica que explore os aspectos sistêmicos das organizações produtivas modernas, facilitando a criação de redes formais e informais de pesquisa, onde estas devem estar inseridas em políticas de desenvolvimento direcionadas na busca por competitividade, baseadas na prática da inovação. No Brasil, a partir da década de 1940, teve início a criação das primeiras instituições de incentivo à tecnologia e ciência, sendo que, ao longo do tempo, diversos fundos setoriais consolidaram-se. O tema da inovação começa a entrar na agenda brasileira no final da década de 1990, sendo que nos anos 2000 passa a ter papel mais ativo em relação ao estímulo de ciência, tecnologia e inovação, valendo-se da criação de novas instituições, leis, programas e incentivos diversos. Nos dias de hoje, a principal fonte de recursos para o financiamento de ciência e tecnologia resulta de recursos assegurados por leis, destacando-se a Lei do Bem, de 2005, que concede benefícios fiscais para compra de equipamentos, P\&D e contratação de pesquisadores, e a Lei de Inovação, de 2004, essa última com foco principal na ampliação de parcerias entre universidades e empresas (MURAN; MARINI; PERONDI, 2016, TORRES-FREIRE; ABDAL; CALLIL, 2012).

Instituições e políticas sempre importam em todos os processos de aprendizado tecnológico e mudança econômica. Os mercados são ambientes nos quais instituições e políticas estão presentes, bem como formas de organização se desenvolvem e onde ocorre a experimentação de novos produtos, sendo que é vital a participação dos governos e de políticas públicas por eles implementadas nos processos de desenvolvimento baseados no conhecimento (TORRES-FREIRE; ABDAL; CALLIL, 2012). Nas políticas públicas do Brasil a inovação necessita investimentos na formação profissional, pesquisa, devendo haver maior participação das esferas locais, ao mesmo tempo em que se preparam profissionais, empresas e grupos para conduzir a inovação como rotina de subsistência e de crescimento nos projetos de desenvolvimento regional (FRANZIN; ALMEIDA; SOUZA, 2014). 
Inovação, políticas públicas de apoio e seus impactos sociais: resgate teórico sobre os temas

Vem ocorrendo ampliação dos investimentos federais e estaduais em infraestrutura de ciência, tecnologia e inovação na criação de instrumentos de apoio à inovação, como incentivos fiscais, linhas de financiamento reembolsáveis e não reembolsáveis, fundos de capital de risco e programas de capital semente. Nesse contexto, oportunidades de desenvolvimento regional e local se abrem, porém, distribuídas de forma desigual no espaço. Assim, torna-se um desafio a maior utilização dos incentivos governamentais de inovação, bem como mecanismos legais por parte do setor produtivo, uma vez que vários incentivos e leis foram criadas, mas a utilização destes, ou mesmo a ciência sobre sua existência ainda é baixa, por parte do setor produtivo. As razões para isso são variadas, ligadas ao desconhecimento dos instrumentos, desinteresse pelo tipo de incentivo ou o entendimento de que estes não são positivos para a empresa, falta de organização da firma em relação às exigências e dificuldades das agências operacionalizarem os incentivos (TORRES-FREIRE; ABDAL; CALLIL, 2012).

Também, há de se frisar a atuação de outros atores no processo de inovação. A ação conjunta de empresas e outros agentes locais favorece a geração de inovações, ocasionando a criação de diferentes tipos de instituições de ensino, pesquisa e prestação de serviços que impactam no aumento da capacidade de inovação do sistema e as externalidades positivas locais. No processo de inovação, as instituições de apoio possuem importante papel, seja no ensino, pesquisa e capacitação técnica ou através de testes, laboratórios, ensaios, centros de P\&D, entidades empresariais, entre outros, difundindo novas tecnologias e aprimorando a competência técnica junto às empresas. A existência de incentivos governamentais auxilia no estabelecimento e atuação dessas instituições. A presença de instituições regionais de apoio é um elemento importante para o sucesso de sistemas locais de produção e inovação, uma vez que os processos de aprendizado tecnológico e inovativo são condicionados por diversos fatores institucionais, organizacionais e socioculturais (Suzigan; Cerrón; Diegues Junior, 2005). Ainda, conforme Souza (2006), resgatando a contribuição da teoria neo-institucionalista, as instituições têm papel importante na questão de influência sobre o resultado das políticas públicas, uma vez que se presume que as instituições tornam o curso de certas políticas mais fáceis do que outras. A teoria ainda auxilia no entendimento de que, além dos indivíduos e grupos possuírem força relevante para influenciarem as políticas públicas, as regras e formais e informais que regem as instituições também possuem.

Muran, Marini e Perondi (2016) afirmam que apesar de as políticas públicas de apoio a inovação priorizarem o desenvolvimento das organizações, é necessário entender que seu impacto vai além, dando voz à população e possibilitando inovações capazes de impactar de forma positiva o desenvolvimento social regional, não se constituindo apenas como inovações materiais. Franzin, Almeida e Souza (2014) colaboram com essa visão, afirmando que a inovação se relaciona diretamente ao desenvolvimento, aplicando-se de à questão social, economia, política e cultura e, caso excluída, impede ou dificulta a consecução de resultados positivos no cenário das políticas públicas. No cerne do processo de desenvolvimento encontram-se a pesquisa, tecnologia, formação, infraestrutura e comércio. Cândido (2002) complementa ao 
Inovação, políticas públicas de apoio e seus impactos sociais: resgate teórico sobre os temas

afirmar que o desenvolvimento regional é obtido com um Estado que cria um ambiente favorável à inovação, disponibilizando bens e serviços públicos e contando com atores chaves para a geração do desenvolvimento, como empresas, redes produtivas, associações e instituições de apoio, além da sociedade civil em geral.

Aprofundando a questão, Franzin, Almeida e Souza (2014) contribuem ao afirmar que a inovação no contexto do Desenvolvimento Regional requer a transformação nos cenários problematizados, valendo-se da criatividade e, nesse sentido, investimentos em estudos, experimentações, testagem e proposições para enfrentar desafios. Assim, uma política de inovação parte do ideal de que o conhecimento tem papel importante no progresso econômico e que a inovação é um fenômeno complexo e sistêmico que demanda recursos e apoio do Estado, uma vez que esta tem causado avanços tecnológicos, diferenciação de produtos e crescente competição mundial por mercados. Políticas públicas de apoio a inovação ampliam de forma significativa ações de impacto social e de estímulo ao desenvolvimento local, sendo importante que os atores políticos e a sociedade civil da região demonstrem interesse por elas, uma vez que possuem o intuito de beneficiar as organizações e impactar o desenvolvimento regional (MURAN; MARINI; PERONDI, 2016).

Nesse contexto de necessidade em demonstrarem interesse, bem como promoverem ação propriamente dita, pode-se citar a colaboração de Abers, Silva e Tatagiba (2018), que desenvolveram abordagem centrada na agência criativa, situada e relacional dos diversos atores, que interagem de forma interdependente nos processos de produção de políticas públicas, confrontando tendências de outros estudos onde o contexto político é abordado como uma estrutura que determina externamente oportunidades e constrangimentos para atuação dos movimentos, o que tira seu poder de agir e participar, constituindo-se como um contexto exógeno, situação dada. Os autores enfatizam a ação dos atores e dos movimentos, afirmando que "[...] agência tem a ver com a capacidade ou o poder de produzir efeitos na realidade. Associar agência com poder não significa entender o agente como livre dos efeitos do poder dos outros" (p. 26). A agência é sempre interação e relação, não ação isolada e, dessa forma, se torna também necessário "[...] entender que os vínculos entre os atores não são estruturas inertes, deterministas, mas formam redes sociais que são ao mesmo tempo préconstruídas e transformáveis" (ABERS, SILVA E TATAGIBA, 2018, p. 27). Apesar dessa reconstrução constante, nem sempre todos os atores participantes possuem os mesmos recursos e capacidades de agir, pelo contrário, a agência do ator é afetada pela sua localização nas estruturas relacionais em que se insere, ou seja, atores tendem a interagir em condições desiguais e, assim, apresentam capacidades de agência desiguais. Porém, reforça-se que estar em desvantagem ou ser marginalizado em uma relação é diferente de estar excluído dela, o que muito importa na abordagem da participação dos movimentos sociais (ABERS, SILVA E TATAGIBA, 2018).

No âmbito municipal, Muran, Marini e Perondi (2016) sugerem incentivos à inovação e empreendedorismo através de leis de apoio à ciência, tecnologia e inovação com o intuito de desenvolver a região e a economia local, tomando-se decisões que privilegiem o fortalecimento de uma cultura empreendedora local. Na visão dos autores, 
Inovação, políticas públicas de apoio e seus impactos sociais: resgate teórico sobre os

temas

uma região empreendedora e inovadora e que destine recursos, iniciativas e políticas a esse fim é capaz de desenvolver práticas sociais capazes de criar mais empregos, ações sociais educativas e culturais, aprimorar a busca pela sustentabilidade, desenvolver acesso à tecnologia e informação, elaborar programas sociais, promover a participação social na gestão pública, entre outras práticas importantes ao bem-estar da população.

\section{Considerações finais}

Este artigo teve como objetivo avaliar a importância da formulação de políticas regionais e iniciativas voltadas à inovação e impacto destas sobre atores sociais., buscando levantar o impacto social da estruturação e estímulo à ecossistemas de inovação, contextualizar políticas públicas, trazendo autores que possam colaborar com isso e avaliar de que forma os atores e movimentos sociais se mobilizam em prol do desenvolvimento de políticas públicas, inclusive focando no estímulo à ecossistemas de inovação.

Após a realização da pesquisa, torna-se evidente que, de forma geral, as definições em relação à política pública adotam a perspectiva de que o todo é mais importante do que a soma das partes e que indivíduos, instituições, interações, ideologia e interesses contam, mesmo existindo diferenças sobre a importância relativa destes. Independente da sua categorização, importante ressaltar a consideração de Souza (2006), que ressalta, através de pressupostos da teoria neo-institucionalista, que a luta pelo poder e por recursos entre os grupos sociais é o cerne da formulação de políticas públicas, sendo essa luta mediada por instituições políticas e econômicas que levam as políticas públicas para certa direção e privilegiam alguns grupos em razão de outros. Também, interagindo, os atores podem se comportar de diferentes formas para influenciar as políticas públicas e se beneficiarem delas,

Focando nos impactos sociais das políticas públicas de apoio à inovação, verificou-se que a ação conjunta de empresas e outros agentes locais favorece a geração de inovações, ocasionando a criação de diferentes tipos de instituições de ensino, pesquisa e prestação de serviços que impactam no aumento da capacidade de inovação do sistema e as externalidades positivas locais. Apesar de as políticas públicas de apoio a inovação priorizarem o desenvolvimento das organizações, é necessário entender que seu impacto vai além, dando voz à população e possibilitando inovações capazes de impactar de forma positiva o desenvolvimento social regional, não se constituindo apenas como inovações materiais. Políticas públicas de apoio a inovação ampliam de forma significativa ações de impacto social e de estímulo ao desenvolvimento local, sendo importante que os atores políticos e a sociedade civil da região demonstrem interesse por ela.

\section{Referências}

ABERS, R. N.; SILVA, M. K.; TATAGIBA, L. Movimentos sociais e políticas públicas: repensando atores e oportunidades políticas. Lua Nova, São Paulo, n. 105, p. 15-46, 
Inovação, políticas públicas de apoio e seus impactos sociais: resgate teórico sobre os temas

Sept.

2018.

Disponível

em

<http://www.scielo.br/scielo.php?script=sci_arttext\&pid=S010264452018000300002\& lng=en\&nrm=iso>. Acesso em $10 \mathrm{dez} .2019$.

CÂNDIDO, G. A. A formação de redes interorganizacionais como mecanismo para geração de vantagem competitiva e para promoção do desenvolvimento regional: o papel do Estado e das políticas públicas neste cenário. REAd - Revista Eletrônica de Administração, Porto Alegre, ed. 28, v. 8, n. 4, jul-ago 2002. Disponível em <http://seer.ufrgs.br/index.php/read/article/view/44129>. Acesso em 1 nov 2019.

CORTES, S. V.; LIMA, L. L. A contribuição da sociologia para a análise de políticas públicas. Lua Nova, 2012, no.87, p.32-62. Disponível em <http://www.scielo.br/pdf/In/n87/03.pdf>. Acesso em 10 dez. 2019.

CRESWEL, J.W. Projeto de Pesquisa - Métodos qualitativo, quantitativo e misto. 3. ed. Porto Alegre: Artmed, 2010.

DAVID, F.; FONSECA, C; PEREIRA, J. Capítulo 3 - Uma breve história da educação como política pública no Brasil. In "Políticas Educacionais no Brasil: o que podemos aprender com casos reais de implementação?" Organização Danilo Leite Dalmon, Caetano Siqueira, Felipe Michel Braga. - São Paulo: Edições SM, 2018

DRUCKER, Peter. Inovação e espírito empreendedor: práticas e princípios. São Paulo: Pioneira

FRANZIN, S. F. L; ALMEIDA, F. M.; SOUZA, C. H. M. A inovação e o desenvolvimento regional como referência para políticas públicas no Brasil. Revista Científica Internacional, Campos dos Goytacazes, n. 29, v. 1, Abril/Junho 2014. Disponível em <http://www.interscienceplace.org/isp/index.php/isp/article/view/282>. Acesso em 31 out 2019.

HOWLET, Michael; RAMESH, M; PERL, Anthony. Política Pública: seus ciclos e subsistemas - abordagem integral. Rio de Janeiro: Elsevier, 2013.

LOPES, L. C. A mobilização política das mulheres negras no Uruguai - considerações sobre interseccionalidade de raça, gênero e sexualidade. Sexualidad, Salud y Sociedad - Revista Latinoamericana, n. 14, pp. 40-65, agosto 2013. Disponível em $<$ https://www.e-

publicacoes.uerj.br/index.php/SexualidadSaludySociedad/article/view/3780/4928>.

Acesso em 10 dez. 2019.

MACIEL, D. A. Ação coletiva, mobilização do direito e instituições políticas - o caso da Campanha da Lei Maria da Penha. Revista Brasileira de Ciências Sociais, v. 26, n. 77, outubro 2011. Disponível em <http://www.scielo.br/scielo.php?script=sci_arttext\&pid=S0102$69092011000300010>$. Acesso em 10 dez. 2019.

MURAN, C. A. B.; MARINI, M. J.; PERONDI, M .A. Políticas públicas de fomento à inovação: uma discussão teórica acerca de possíveis resultados para o desenvolvimento regional. Anais do 29 Congresso Internacional de Administração - ADM 2016, 13 a 16 de setembro de 2016, Natal-RN. Disponível em < http://www.admpg.com.br/2016/down.php?id=2048\&q=1.>. Acesso em 2 nov 2019. 
Inovação, políticas públicas de apoio e seus impactos sociais: resgate teórico sobre os temas

REGO, W. L. Aspectos teóricos das políticas de cidadania: uma aproximação ao Bolsa Família. Lua Nova, n.73, 2008, p. 147-185. Disponível em <http://www.scielo.br/pdf/ln/n73/n73a07>. Acesso em 10 dez. 2019.

SANTOS, M. A. O. Políticas de ação afirmativa comparadas no Brasil e na Colômbia. Ciências Sociais Unisinos, v. 52, n. 2, p. 137-148, maio/agosto 2016. Disponível em <http://revistas.unisinos.br/index.php/ciencias_sociais/article/view/csu.2016.52.2.01> . Acesso em 10 dez. 2019.

SCHUMPETER, Joseph. A teoria do desenvolvimento econômico. São Paulo: Abril, 1985 (Coleção Os Economistas) 1912.

SOUZA, Celina. Políticas públicas: uma revisão da literatura. Sociologias, Porto Alegre, Ano 8, no 16, p. 20-45, jul./dez. 2006. Disponível em <http://www.scielo.br/pdf/soc/n16/a03n16>. Acesso em 10 dez. 2019.

SUZIGAN, W.; CERRÓN, A. P. M; DIEGUES JUNIOR, A. C. Localização, inovação e aglomeração: o papel das instituições de apoio às empresas no Estado de São Paulo. São Paulo em Perspectiva, v. 19, n.2, p. 86-100, abri-jun 2005. Disponível em <http://www.scielo.br/pdf/spp/v19n2/v19n2a08.pdf >. Acesso em 1 nov 2019.

TIDD, Joe. BESSANT, John; PAVITT, Keith. Gestão da Inovação. 3a ed. Porto Alegre: Bookman, 2008.

TORRES-FREIRE, C.; ABDAL, A.; CALLIL, V. Infraestrutura de ciência, tecnologia e inovação no Estado de São Paulo e a necessidade de políticas públicas de desenvolvimento baseadas no território. Anais do 36 Encontro Anual da ANPOCS - Associação Nacional de Pós-Graduação e Pesquisa em Ciências Sociais. 21 a 25 de outubro de 2012, Águas de Lindoia/SP. Disponível em <http://www.anpocs.com/index.php/papers-36encontro/gt-2/gt37-2/8286-infraestrutura-de-ciencia-tecnologia-e-inovacao-noestado-de-sao-paulo-e-a-necessidade-de-politicas-publicas-de-desenvolvimentobaseadas-no-territorio/file >. Acesso em 1 nov 2019.

VIOLA, S.; PIRES, T. V. Os difíceis ecos dos direitos humanos: participação e cultura entre as gerações. Revista Debates (UFRGS), v. 8, p. 83-102, 2014. Disponível em <http://www.seer.ufrgs.br/index.php/debates/article/view/49507/31158>. Acesso em 10 dez. 2019

\section{Sobre o autor:}

Alexandre Aloys Matte Júnior, Doutorando em Economia - PPG em Economia Unisinos. Email: alexandrejr1408@gmail.com 